\title{
PENGUATAN KAPASITAS KELEMBAGAAN PLS DALAM MEMASUKI ERA KOMPETITIF MEA
}

\section{Oong Komar}

\author{
Dosen PLS Universitas Pendidikan Indonesia, \\ email: oongkomar@yahoo.com
}

\begin{abstract}
Abstrak
PLS (pendidikan luar sekolah) adalah modus pendidikan kreatifitas, yaitu usaha pendidikan yang kesengajaan/berlangsungannya di dasarkan pilihan keinginan/kebutuhan dan kesungguh-sungguhan belajar peserta didik dari masyarakat tertentu, sehingga penyelenggaraan PLS berbeda dengan sekolah terutama menyangkut sistem pengelolaan materi/isi, media dan waktunya yang acapkali disesuaikan dengan kesempatan peserta didiknya. Ternyata kiprah PLS meliputi kelembagaan, program aksi dan ketenagaan, yang stake-holdernya tersebar, yaitu berada di masyarakat, praktisi, ahli dan pemerintahan, sehingga kondisi PLS bak seluas samudra dan seolah kompleksitas suatu spektrum. Namun, PLS yang sangat dibutuhkan masyarakat, dalam optimalisasi pelaksanaannya masih jauh dari harapan. Saat ini jumlah dan kualitas ketenagaan PLS masih belum standar dan yang menjadi penyuplai akademisnya (kelembagaan, program dan ketenagaan) pun hanya setingkat jurusan dan program studi. Kebutuhan nyata masyarakat mestinya mendorong peningkatan lembaga akademis PLS setidanya setingkat fakultas.

Oleh karena itu, PLS perlu mengubah prioritas kegiatan, yang saat ini PLS berorientasi program harus diubah menjadi berorientasi penataan kelembagaan, seperti pembagian kerja antar stakeholder di pusat pemerintahan hingga daerah, peningkatan kemampuan organisasi, menata jaringan kerja, kemampuan layanan, spesifikasi disiplin ilmu, profesionalisasi ketenagaan dan kejelasan lokasi lapangan prakteknya.
\end{abstract}

Kata Kunci: PLS, Lingkup PLS, Tenaga PLS, Kapasita Lembaga PLS

\section{A. Masalah}

\section{PLS “Penyelamat” Kebutuhan Pendidikan Masyarakat}

Kiprah PLS sering menjadi aspirasi lahirnya solusi alternative pendidikan atau penyelamat. Contoh, siswa yang tidak lulus ujian nasional SMP atau SMA mendapat "penyelamatan" dengan mengikuti ujian persamaan Paket B atau C. Akibat masyarakat yang ragu pada sekolah, muncul alternatif rumah sekolah. Lembaga bimbingan belajar dijadikan alternatif persiapan menghadapi UN oleh sejumlah masyarakat.

Ketika sekolah masih langka, orang berusaha membebaskan diri dari ketergantungan dengan mengikuti program latihan. Ketika manusia terdidik masih langka, Ia (tenaga PLS) tetap mengabdikan diri untuk membebaskan buta huruf. 
Saat ini untuk lolos menembus "lubang jarum" saringan masuk perguruan tinggi, banyak siswa menyiapkan diri mengikuti bimbingan belajar. Selain itu, sejumlah masyarakat yang akan memasuki dunia kerja, menyiapkan diri mengikuti kursus bahasa, komputer atau pengemudi, agar memenangi persaingan seleksi pegawai.

Ivan Illich (1974) memandang PLS sebagai alternative to schooling. Oleh karena itu, masyarakat harus membuang anggapan bahwa hanya sekolah yang mampu memberi bekal bermutu. Padahal PLS pun terbukti dalam banyak hal menjadi pendidikan alernatif atau penyelamat.

\section{PLS Hidup dengan Pandangan "Sebelah Mata"}

Dikala manusia yang mengenyam sekolah masih langka, sebenarnya telah tumbuh dalam masyarakat suatu gerakan pendidikan yang disebut pendidikan masyarakat atau pendidikan di luar sekolah (PLS). Kendati gerakannya terbukti survive, tetapi masih dianggap "kecil" dan dipandang "sebelah mata". Gerakan PLS, begitu tidak dianggap berartinya, Ia tidak eksis dalam UU No. 4/1950 tentang Dasar Pendidikan dan Pengajaran.

Meskipun begitu, tak menyurutkan diri, gerakan pendidikan masyarakat terus makin tumbuh subur, sampai akhirnya terekam oleh TAP MPR No IV/1978 tentang GBHN, berbunyi "pendidikan juga menjangkau program luar sekolah, yaitu pendidikan yang bersifat kemasyarakatan". Dengan TAP tersebut, gerakannya semakin nyata dan dinamis, sehingga dalam TAP MPR No II/1983 dimasukkan ke dalam Bab Pendidikan.

Dalam perjalanan selanjutnya, gerakan PLS terbukti makin semarak dan memiliki daya tahan hidup yang tinggi, maka wajar tersurat dalam UU No 2/1989 tentang Sisdiknas sebagai salah satu jalur pendidikan di samping jalur sekolah. Bahkan dalam UU itu, dianggap kurang memadai lagi, sehingga perlu disempurnakan agar sesuai dengan perkembangan masyarakat. Usaha penyempurnaannya sebagaimana yang terbit dalam UU No. 20/2003 tentang Sisdiknas.

Secara logis, daya tahan hidup (survive) PLS dimungkinkan karena (a) gerakannya berakar kuat pada masyarakat berhubung menyangkut kebutuhan dan kesadaran untuk maju, (b) kreativitas lembaga PLS menawarkan perubahan dan pembebasan dari ketergantungan, (c) dipandang sebagai alternatif pilihan untuk menata masa depan melalui penciptaan lapangan kerja, dan (d) turut serta mencerdaskan masyarakat dengan sikap otodidak dan ulet. Artinya, PLS merupakan alternatif pendidikan untuk menjadi sukses, pandai dan berhasil (kreatif).

Selain itu, salah satu program unggulan PLS ialah pendidikan kesetaraan. Program ini dikenal dengan sebutan Paket A, Paket B, dan Paket C. Program ini banyak dimanfaatkan masyarakat, terutama siswa yang hasilnya kurang beruntung dalam mengikuti UN. Masyarakat memanfaatkan pendidikan kesetaraan pun untuk berbagai tuntutan persyaratan. Pendidikan kesetaraan ini diakui hasilnya untuk melanjutkan sekolah/kuliah dan memasuki dunia kerja. Sehingga, akhir-akhir ini pendidikan kesetaraan menjadi semakin populer. 
Sebenarnya penganugrahan gelar DR (HC) kepada seseorang yang memenuhi syarat, telah eksis lebih dulu dari pada kehadiran Paket A, B, dan C, padahal hakekat DR (HC) merupakan pendidikan kesetaraan jenjang PT dan merupakan bukti pengakuan atas keberhasilan PLS. Meskipun hal itu belum menjadi wacana masyarakat, dan belum tersurat dalam perundang-undangan sebagai program kesetaraan PLS. Kendati begitu, masyarakat mestinya melepas anggapan bahwa pendidikan hanya sekolah, padahal hasil PLS pun dapat disetarakan dengan sekolah, bahkan sampai kesetaran PT sebagaimana gelar DR (HC).

Program PLS ke depan kiranya perlu menuju masyarakat belajar atau masyarakat yang mampu memanfaatkan realita untuk belajar. Yaitu belajar dari situasi dan yang tengah dihadapi, belajar berusaha sendiri dalam mengatasi masalah. Masyarakat belajar merupakan usaha menolong dirinya. Dari masyarakat belajar akan tumbuh sikap enggan menunggu uluran pihak lain.

Hasil dari masyarakat belajar dapat menciptakan lapangan kerja sendiri. Contoh, seorang penjahit "jalanan" dengan tulus mengangkat asisten seorang anggota masyarakat yang dipandang memiliki dedikasi, ulet dan jiwa wirausaha. Penjahit ini, dalam jiwanya tak terlintas pikiran bahwa asistennya itu kelak akan menjadi calon saingan. Bahkan, terus dipupuk keterampilannya menuju kemandirian, agar mampu merintis usaha sendiri. Dan terbukti banyak yang berhasil. Kegiatan ini dalam istilah ilmiah disebut career education dan juga magang.

\section{PLS Bak "Seluas Samudra"}

PLS "hidup" seiring kebutuhan masyarakat. Di antaranya dibutuhkan untuk pemberdayaan diri, peningkatan keterampilan kerja, penyesuaian diri dan penyesuaian dengan lingkungan. Bahkan kebutuhan inservice training pekerja untuk memenuhi tuntutan profesionalitas dan layanan prima.

Pilihan PLS oleh sejumlah masyarakat disebabkan pembelajarannya bersifat instant dan dapat ditempuh sambil bekerja. Selain itu, PLS dijadikan sebagai (1) wahana pendidikan alternatif, (2) cara belajar untuk maju, mandiri, wirausaha dan kerja kreatif, (3) mengembangkan watak lepas dari ketergantungan dan mencitptakan lapangan kerja, (4) magang dan (5) penciptaan iklim masyarakat belajar (learning society).

Kiprah PLS secara nasional meliputi kelembagaan, program aksi dan ketenagaan. Pertama, kelembagaan PLS meliputi: PAUD (kelompok bermain, TPA, TK/RA dan yang sejenis), PKBM, Kursus, TBM, Forum satuan PLS (Majelis Taklim, Organisasi Perempuan, HIPKI, HISPPI, Asosiasi Propesi Kursus, Forum PAUD, Forum PKBM, dan sebagainya), UPT P2PNFI dan BPPNFI, UPTD BPKB dan SKB.

Kedua, program aksi PLS meliputi: PAUD, keaksaraan fungsional, Paket A, B, dan C, kursus, KBU, magang, peningkatan budaya baca dan perpustakaan, pengarusutamaan jender, program PLS sejenis seperti life skills, beasiswa, belajar jarak jauh dan pendidikan maya.

Ketiga, ketenagaan PLS terdiri atas pendidik dan tenaga kependidikan. Pendidik PLS meliputi: (1) pamong belajar UPT P2PNFI dan BPPNFI, UPTD BPKB/SKB, (2) fasilitator 
desa intensif (FDI), (3) tutor KF, (4) tutor Paket A, B, C, (5) pendidik dan pengasuh PAUD, (6) pendidik dan penguji praktek kursus, (7) nara-sumber teknis KBU, (8) pendidik PLS sejenis, seperti instruktur diklat, magang, widyaiswara dan penyuluh.

Sementara, tenaga kependidikan PLS meliputi: (1) penilik, (2) tenaga lapangan dikmas (TLD), (3) pengelola PKBM, (4) pengelola kelompok belajar, (5) pengelola kursus, (6) pengelola TBM, (7) pengelola PAUD dan (8) tenaga kependidikan satuan PLS lainnya (pengelola KBU/magang, laboran, pustakawan, dan sebagainya).

Oleh karena itu, kondisi PLS seolah merupakan kompleksitas suatu spektrum dan bak seluas samudra. PLS sangat dibutuhkan masyarakat, tetapi ternyata optimalisasinya masih jauh dari harapan. Saat ini yang menjadi penyuplai akademis (kelembagaan, program dan ketenagaan) hanya setingkat jurusan dan program studi. Kebutuhan nyata masyarakat mestinya mendorong peningkatan lembaga akademis PLS setingkat fakultas.

\section{B. Solusi}

\section{Penguatan Kapasitas Kelembagaan PLS}

Capacity development adalah sebuah pendekatan yang sekarang secara luas digunakan dalam community development. Istilah ini telah digunakan sejak tahun 1990-an oleh negara-negara donor untuk memperbaiki kapasitas negara partner (negara yang mendapat bantuan). Upaya pengembangan kapasitas merupakan bagian yang penting di dalam berbagai aspek kehidupan. Pentingnya bagi aparatur pemerintahan untuk meningkatkan performa aparatur dalam menjalankan tugasnya sebagai abdi negara, menjalankan regulasi dan deregulasi kebijakan pemerintahan, sehingga dalam konteks pembangunan secara keseluruhan pun upaya pengembangan kapasitas menjadi bagian yang tidak terpisahkan. Artinya, tidak mungkin terjadi suatu proses pengembangan dalam hal apapapun tanpa upaya pengembangan kapasitas bagi pelaku maupun juga sistem yang mengaturnya.

Di antaranya melalui penguatan kapasitas (Capacity Building) yaitu serangkaian strategi yang ditujukan untuk meningkatkan efisiensi, efektifitas, dan responsifitas dari kinerja. Artinya, sebagai kemampuan dari suatu organisasi atau perusahaan untuk menciptakan nilai dimana kemampuan tersebut didapatkan dari berbagai jenis sumber daya yang dimiliki oleh perusahaan.

Tujuan Capacity Building yaitu : Secara umum untuk perwujudan sustainabilitas suatu sistem. Secara khusus untuk mewujudkankinerja yang lebih baik dilihat dari: (1) Efisiensi waktu (time) dan sumber daya (resources) yang dibutuhkan mencapai suatu outcome. (2) Efektifitas berupa kepantasan usaha yang dilakukan demi hasil yang diinginkan. (3) Responsifitas yakni bagaimana mensinkronkan antara kebutuhan dan kemampuan maksud tersebut. (4) Pembelajaran yang terindikasi pada kinerja individu, group, organisasi dan sistem.

Manfaat kegiatan Capacity Building dalam pengembangan sumber daya manusia, untuk: (1) Mengurangi dan menghilangkan kinerja yang buruk. (2) Meningkatkan produktivitas. (3) Meningkatkan fleksibilitas dari angkatan kerja. (4) Meningkatkan komitmen karyawan. (5) Mengurangi turn over dan absensi. 
Oleh karena itu, penguatan kapasitas akan mengubah secara sistematis dan konsisten sistem mekanisme kerja organisasi yang berpola pikir (mind-set) dan berbudaya kerja (culture-set) belum efisien, efektif, produktif, profesional serta birokrat yang belum memiliki pola pikir melayani masyarakat, belum mencapai kinerja yang lebih baik (better performance), dan belum berorientasi pada hasil (outcomes). Pelayanan publik belum dapat mengakomodasi kepentingan seluruh lapisan masyarakat dan belum memenuhi hak-hak dasar warga negara/penduduk. Penyelenggaraan pelayanan publik belum sesuai dengan harapan bangsa yang semakin maju dalam persaingan global yang semakin ketat.

Sehingga, PLS dituntut penguatan kapasitas kelembagannya, seperti mempertimbangkan prodi PLS setingkat fakultas, mengubah orientasi program ke orientasi penguatan kapasitas kelembagaan PLS dan membangun jejaring kerja.

\section{a. Pertimbangan Peningkatan Prodi PLS Setingkat Fakultas.}

PLS dibebani tugas melaksanakan komitmen dunia melalui program aksi pendidikan untuk semua (EFA) dan tujuan pembangunan millennium (MDGs), bahkan mulai tahun 2016-2030 dilanjutkan dengan SDGs. Sasaran EFA terdiri atas: pendidikan usia dini, pendidikan dasar formal, life skill, keaksaraan, kesetaraan jender dalam pendidikan dan peningkatan mutu pendidikan. Adapun sasaran MDGs terdiri atas (a) penghapusan kemiskinan dan kelaparan ekstrem, (b) pendidikan dasar untuk semua, (c) promosi kesetaraan jender dan pemberdayaan perempuan, (d) penurunan angka (jumlah) kematian anak, (e) perbaikan kesehatan ibu hamil, (f) penghentian penyebaran HIV/AID, malaria dan penyakit lainnya, (g) pembangunan berwawasan lingkungan yang berkelanjutan, dan (h) kemitraan global dalam perdagangan dan sistem keuangan.

Sasaran nasional program PLS meliputi: (a) pendidikan kesetaraan untuk mendukung kesuksesan wajib belajar pendidikan dasar 9 tahun, (b) pendidikan keaksaraan fungsional untuk kesuksesan penurunan jumlah penduduk buta aksara usia 15 tahun ke atas, (c) PAUD untuk persiapan anak masuk sekolah, (d) kursus dan pelatihan untuk pemenuhan kebutuhan belajar masyarakat, (e) life skill untuk membekali warga belajar hidup mandiri, (f) pemberdayaan perempuan untuk pengarusutamaan jender bidang pendidikan, (g) budaya baca masyarakat untuk peningkatan kualitas pendidikan masyarakat, dan (h) pengembangan kelembagaan pendidikan nonformal untuk menunjang keberhasilan programnya.

Sasaran program PLS, kesuksesannya sangat tergantung pada kuantitas dan kualitas ketenagaan PLS. Prakiraan kebutuhan ketenagaan nasional PLS seluruhnya 569.790 tenaga. Jumlah ketenagaan yang ada sekitar 25,5\%. Sebanyak 1,65\% berstatus PNS dan 98,35\% bukan PNS. Adapun kualitas ketenagaan PLS masih jauh dari harapan.

Oleh karena itu, lima tahun mendatang, kondisi PLS menghadapi permasalahan ketenagaan, baik jumlah maupun kualitasnya, seiring tantangan pendidikan nasional menghadapi masalah kinerja out put satuan pendidikan untuk meningkatkan daya saing.

Pemecahan masalah ketenagaan PLS dengan syarat kualifikasi akademis S1 dan kualifikasi sertifikasi profesional pendidik akan lambat bila lembaga akademis masih 
setingkat jurusan dan program studi. Karena itu, perlu peningkatan lembaga akademis PLS menjadi setingkat fakultas.

Pertimbangan PLS setingkat fakultas, tidak hanya berkaitan dengan kiprahnya, tetapi juga berdasarkan analisis yuridis. Undang-Undang Nomor 20 Tahun 2003 tentang Sistem pendidikan Nasional, mengatur eksistensi PLS, terutama Pasal 26 Pendidikan Nonformal, Pasal 27 Pendidikan Informal dan Pasal 28 PAUD. Bahkan, Pasal 30 Pendidikan Keagamaan dan Pasal 31 Pendidikan Jarak Jauh, kiranya termasuk cakupan PLS.

\section{b. Mengubah Orientasi Program ke Orientasi Penguatan Kapasitas Kelembagaan PLS.}

Menurut Umbirtu Sihombing (1999: 20) dalam pelaksanaannya program PLS yang terdapat di masyarakat terdapat dua jenis kelompok: (a). Program Pokok yaitu program PLS yang diadakan oleh pemerintah, seperti program pemberantasan buta aksara dan pendidikan dasar, masing-masing program ini terdiri dari pengembangan anak usia dini, kejar paket A setara SD, kejar paket B setara SMP, kejar paket C setara SMA. Program pendidikan berkelanjutan, terdiri dari program: kejar usaha, kursus, pembinaan kursus, dan pendidikan kewanitaan.

(b). Program Penunjang, yaitu program PLS berupa kegiatan rintisan-rintisan berdasarkan perundang-undangan yang berlaku serta berdasarkan kebutuhan masyarakat, seperti program pemberdayaan ekonomi pedesaan, program kursus masuk desa, penyediaan dan pengembangan sarana belajar pokok dan pelengkap, antara lain melalui latihan ketenagaan, bantuan teknis,serta monitoring dan evaluasi.

Adapun sasaran program PLS meliputi seluruh warga masyarakat yang membutuhkan pendidikan berhubung warga tersebut tidak dapat/sempat mengikuti pendidikan di jalur sekolah sepenuhnya, usia warga masyarakat yang harus dibelajarkan tidak terbatas, namun secara prioritas diutamakan mereka yang berusia 10-44 tahun. Jika diklasifikasikan sasaran pendidikan masyarakat menjadi warga masyarakat yang buta huruf,putus sekolah antar jenjang,lulus sekolah tidak melanjutkan, pencari kerja yang menuntut ketrampilan tertentu dan mereka yang sudah bekerja tetapi ingin meningkatkan jenjang karir dan perlu memenuhi persyaratan ketrampilan.

Saat ini PLS secara nasional memiliki program utama, yang garis besarnya terdiri atas: (a). Layanan pendidikan keaksaraan dan Multi Keaksaraan, (b). Layanan pendidikan Orang Dewasa, Pemberdayaan Perempuan dan Anak, (c). Layanan Peningkatan Budaya Baca, (d). Layanan Pengarusutamaan gender dalam bidang Pendidikan, (e). Layanan Rintisan Program dan (f). Layanan Penataan Kelembagaan.

Program PLS lainnya, yaitu: Program pengarustamaan gender untuk dalam membatasi jumlah anak dalam suatu keluarga secara umum atau massal sehingga dapat mengurangi jumlah angka kelahiran serta pengetahuan pentingnya menunda masa perkawinan. Program kecakapan hidup (KWK, KWD, PKH) dalam rangka penambahan dan penciptaan lapangan kerja. Program PAUD, Pendidikan keaksaraan serta pendidikan Kesetaraan Paket A, B dan C guna meningkatkan kesadaran dan pendidikan kependudukan. 
Program PLS di atas tampak kurang berpihak pada program peningkatan kapasitas kelembagaan PLS. Dimana program peningkatan kapasitas kelembagaan PLS, terdiri atas delapan jenis, yaitu: Peningkatan Mutu Dikmas Melalui Kerjasama Perguruan Tinggi (PT), Pendampingan Rumah Pintar, peningkatan Kapasitas Kelembagaan PSW/PSG, Penguatan Balai Belajar Bersama, Pendampingan PKBM, Peningkatan Mutu Kelembagaan PKBM, dan Peningkatan Mutu Forum Komunikasi PKBM dan Lembaga Sejenis. Tentu saja bila di terapkan seiring dengan kondisi kelembagaannya baik, maka program-program PLS mampu menjawab tantangan masa depan dan permasalahanpermasalahan kehidupan bermasyarakat.

\section{c. Membangun Jejaring Kerja}

Praktik birokrasi cenderung percaya kepada kemampuan sendiri dalam pemecahan berbagai persoalan pelaksanaan pembangunan. Selain itu, kurang fleksibel dalam melaksanakan tugas-tugas pelayanan terhadap masyarakat, serta belum dapat menjawab tuntutan yang terus berkembang cepat. Konsekwensinya, menimbulkan resiko dampak negatif, seperti inefisiensi dan inefektivitas pelaksanaan pembangunan. Praktik-praktik birokrasi yang kurang menguntungkan bagi terciptanya tanggungjawab tugas-tugasnya kepada masyarakat dalam jangka panjang sudah tidak mungkin lagi diteruskan.

Bahkan, trend globalisasi dan demokratisasi menuntut penyelenggaraan pemerintahan yang profesional (good governance), sehingga mengharuskan birokrasi melakukan reinventing government agar birokrasi tidak kehilangan momentum dalam setiap perubahan yang terjadi di masyarakat.

Oleh karena itu, melalui program pembangunan jejaring kerja, kemitraan dan kerja sama erat yang saling mendukung, maka dalam jangka panjangsaling menguntungkan. Membangun jejaring kerja hakekatnya adalah proses membangun komunikasi, berbagi ide, pertukaran informasi dan sumber aya atas dasardalam bentuk nota kesepahaman atau kesepakatan (Mou).

Dengan pola kerjasama dan kemitraan pada akhirnya, (1) secara gradual dalam jangkapanjang menempatkan pemerintah berposisi fasilitator, mediator, dan advokator dalam segenap pelaksanaan proses pembangunan, sehingga beban birokrasi(bureaucracy burden) akan relatif ramping. (2) Masyarakat pun mengambil inisiatif yang bersifat aspiratif-partisipatif-proaktif dalam keterlibatannya di setiap tahap pelaksanaan proses pembangunan.

Dalam kerangka pengembangan sumber daya manusia yang berkualitas dan berorientasi masa depan yang akan menjadi pilar utama pembangunan di berbagai sektor, pendidikan luar sekolah dapat memegang peranan yang sangat strategis. Pendidikan luar sekolah baik yang dilaksanakan pemerintah maupun yang dilaksanakan swasta ataupun masyarakat. dalam arti mereka yang tertarik melakukan pendidikan yang berorientasi masa depan melalui pendidikan luar sekolah dapat mengambil peran yang lebih nyata di masyarakat.

Jaringan kerja merupakan suatu sistem kerja sama antara pusat dengan daerah, antardaerah, dan antarunsur di daerah dalam mengembangkan satuan-satuan PLS yang 
sesuai dengan karakteristik, kebutuhan, dan perkembangan daerah. Model Jejaring PLS dikembangkan dengan tujuan: (1). membangun jaringan kerja sama antara pusat dan daerah, serta antardaerah, (2). membantu daerah dalam membentuk dan memberdayakan Tim Jaringan sesuai dengan kondisi dan kebutuhan masing-masing.

Organisasi Jaringan kerja PLS berkedudukan di pusat, provinsi, dan kabupaten/kota. Di tingkat pusat dikordinasikan oleh Direktorat PAUD dan Penmas. Di tingkat provinsi dikoordinasikan oleh Kasi Dikmas Dinas Pendidikan Provinsi. Di tingkat Kabupaten/Kota dikoordinasikan oleh Kasi Dikmas Dinas Pendidikan Kabupaten/Kota.

Dalam melaksanakan tugasnya, Tim Jaringan Kerja PLS bekerja sama dengan lembaga terkait. Koordinasi Jaringan Kerja PLS dilakukan melalui pembagian tugas dan wewenang, perencanaan kegiatan bersama, pemantauan pelaksanaan kegiatan, dan kaji silang kegiatan yang telah dilakukan. Sementara koordinasi antar-jaringan dilakukan melalui rapat atau pertemuan rutin/ berkala pada tingkat pusat dan daerah.

\section{Spesifikasi Disiplin ilmu PLS.}

PLS berfungsi melayani kebutuhan pendidikan di luar sistem sekolah, sehingga kehdirannya sebagai bidang layanan masyarakat khusus. Yaitu untuk (1) meningkatkan kualitas hidup bagi masyarakat tertinggal (pengentasan), dan (2) membebaskan masyarakat yang tertindas (pemberdayaan). Profesi PLS harus melakukan layanan yang baik terhadap kliennya. Layanan yang baik ditopang disiplin ilmu yang kokoh. Sehingga profesi PLS harus melakukan layanan yang baik dan ditopang disiplin ilmu yang kokoh.

Paling tidak, ada dua asumsi pemikiran keilmuan PLS. Pertama, masyarakat yang tertinggal disebabkan kelemahan sendiri. Fungsi layanan PLS bagi masyarakat tertinggal adalah meningkatkan kualitas SDM dan mengentaskannya menuju tarap hidup yang lebih baik. Andragogi termasuk disiplin ilmu PLS utama yang menopang upaya peningkatan masyarakat tertinggal. Prinsip-prinsip Andragogi: (1) menganggap manusia bersifat dewasa, (2) manusia memiliki kekayaan pengalaman, (3) siap belajar yang praktis.

Kedua, masyarakat yang terlantar disebabkan struktur sosial yang hegemoni. Fungsi layanan PLS bagi masyarakat tertindas adalah melakukan pemberdayaan dan pembebasan menuju terciptanya transformasi sosial yang bebas dari struktur sosial yang hegemoni. Pedagogik Kritis termasuk disiplin ilmu PLS utama yang menopang upaya pembebasan terlantar/tertindas. Prinsip-prinsip Pedagogik kritis: (1) penyadaran diri melalui refleksi, aksi, kreasi dan kritisi (evaluatif/assessment), (2) transformatif emensipatoris.

Selain itu, disiplin ilmu PLS memiliki sifat akademik dan profesional. Yang bersifat akademik adalah bidang kajian dengan obyek disiplin ilmu layanan PLS pada aktivitas yang melembaga. Sementara yang bersifat profesional adalah bidang layanan dengan obyek operasional kelembagaan dan gerakan praktisi PLS.

\section{Profesionalisasi PLS dan lapangan prakteknya.}

Istilah profesi telah dimengerti setiap orang, yaitu bidang keahlian yang dihasilkan dari 
pendidikan (tinggi), yaitu penguasaan ilmu/teori yang mendasari praktek pelaksanaan, dan hubungan antara teori dan penerapan dalam praktek. Profesi memiliki tolak ukur perilaku, paling tidak ada suatu kejelasan mengenai pola perilaku yang baik dalam rangka kepentingan masyarakat. Sehingga standar profesional akan menciptakan suatu kualitas masyarakat semakin baik.

Profesi memiliki Watak Kerja, yaitu: (1) Kerja beritikad merealisasikan kehormatan profesi yang digeluti, tanpa mementingkan atau mengharapkan imbalan upah materiil, (2) Kerja dilandasi kemahiran teknis yang berkualitas tinggi yang dicapai melalui proses pendidikan dan/atau pelatihan yang panjang dan ekslusif. (3) Kerja berpedoman pada kualitas moral pada sebuah mekanisme kontrol berupa kode etik yang dikembangkan dan disepakati bersama di dalam sebuah organisasi profesi.

Gambar proses profesionalisasi PLS, sebagai berikut:

\section{Proses Profesionalisasi}

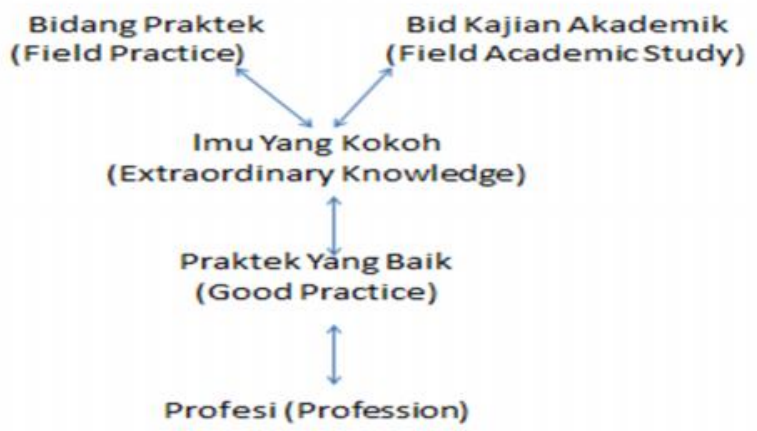

Oleh karena itu, tenaga PLS dalam memberikan layanan profesionalnya harus: (1) merasa panggilan jiwa dalam melayani kliennya, (2) dibekali disiplin ilmu yang kokoh dalam menunaikan tugasnya, dan (3) memiliki kode etik PLS guna melindungi otonomi profesinya.

Profesi PLS, sebagai berikut:

- Pamong Belajar

- $\quad$ TLD (Tutor, Fasilitator, Instruktur, Widyaiswara, Penyuluh, Kader masyarakat)

- Penilik PLS

- Pendampingan/Pemberdayaan

- $\quad$ Pengelola PKBM (Rumpin, KF, Paket, PAUD, Parenting, Kons-Keluarga )

\section{PENUTUP}

Untuk peningkatan kapasitas kelembagaan PLS dalam memasuki era kompetitif MEA, kata kuncinya adalah: akses kepada informasi, sikap inklusif dan partisipatif, akuntabilitas, dan pengembangan organisasi lokal. Terdapat dua prinsip dasar yang seyogyanya dianut. Pertama, menciptakan ruang atau peluang bagi masyarakat untuk mengembangkan dirinya secara mandiri dan menurut cara yang dipilihnya sendiri. Kedua, mengupayakan agar masyarakat memiliki kemampuan untuk memanfaatkan ruang atau peluang yang tercipta tersebut. Sementara itu ada lima garapan yang perlu dilaksanakan, yaitu penyediaan pelayanan dasar, peningkatan kapasitas pemerintahan 
lokal, peningkatan kapasitas pemerintahan nasional, pengembangan pasar yang pro rakyat, dan pengembangan akses untuk bantuan keadilan dan hukum.

\section{Pustaka Rujukan}

Coombs, P.H. et al. (1973). New Path to Learning for Rural Children and Youth. New York: International Council for Education Development.

and Ahmed, M. (1984). Attacking Rural Poverty, How Nonformal Education Can Help. Diterjemahkan oleh Yayasan Ilmu-Ilmu Sosial. Jakarta: C.V. Rajawali.

deJong, J.C.N. (1984). Sosiologi Pendidikan, Suatu Ihtisar Teoretis tentang Pendidikan, Perkembangan dan Modernisasi. Jakarta: Sangkala Pulsar.

Departemen Pendidikan Nasional. (2003). Undang-Undang No. 20 Tahun 2003 Tentang Sistem Pendidikan Nasional. Jakarta: Depdiknas.

Fakultas Ilmu Pendidikan IKIP Bandung. (1981). Pengarahan Menteri P dan K Republik Indonesia. Laporan Hasil Munas ISMS. Bandung: FIP-IKIP.

Gerstner, L.V. et al. (1995). Reinventing Education Entrepreneurship in America's Public Schools. New York: Publishid by Plum.

Hassan, F. (1984). Filsafat Pendidikan Tinggi. Jurnal Thesa. 2. 4-11.

Illich, I. (1974). Deschooling Society. London: Galder \& Boyars.

Kian Gie, K. (1984). "Beberapa Bentuk Konkret Kontribusi Pengusaha dalam Pembangunan Nasional”. Jurnal Analisa. 11, 867-877.

Soelaiman, J (2004), Konsep Dasar Pendidikan Luar Sekolah. Jakarta: PT. Bumi Aksara.

Syuaeb, J (2002), Pendidikan Luar Sekolah. Cirebon: CV. Alawiyah.

Sanapiah, F (1981), Pendidikan Luar Sekolah . Surabaya: CV. Usaha Nasional.

Sihombing Umberto, (1999) Pendidikan Luar Sekolah, Jakarta. Mahkota.

Sudarsono, J. (1998). Pembaharuan Pendidikan Nasional dalam Era Reformasi. Jurnal Ilmiah Kajian. 015. 4-10.

Wahyudi, R. (1994). Peranan Pendidikan dalam Pengembangan Masyarakat Miskin. Jakarta. PT Raja Grafindo Persada.

Yoesoef, D. (1984). Peranan Dunia Usaha dan Kewirausahaan dalam Pembentukan Bangsa. Jurnal Analisa. 11, 861-867.

http://www.bp3ls.dikmentidkia.go.id/skb-jaksel.phpSH/emmy kuswandari, artikel Pendidikan Luar Sekolah (internet)

http://nidaimekingofblue.blogspot.com/2011/05/pengembangan-kapasitassumberdaya.html.

ebook-pdf.org/.../twelve-principles-for-effecti

en.wikipedia.org/.../The_Seven_Habits_of_Hi

en.wikipedia.org/wiki/Reg_Revans

eprints.undip.ac.id/9664/1/MANAJEMEN

http: //seputarpengertian.blogspot.com/2014/04/pengertian-tutor.html) 